\title{
The Propositional vs. Hermeneutic Models of Cross-Cultural Understanding
}

\author{
Xinli Wang \\ Philosophy Department \\ Juanita College \\ Huntingdon \\ PA, 16652 \\ USA \\ Email: wang@juanita.edu

\section{Ling Xu} \\ Nagoya University of Commerce and Business \\ Nagoya \\ Japan \\ Email: lingxu921@hotmail.com
}

\begin{abstract}
What the authors attempts to address in this paper is a Kantian question: not whether, but how is cross-cultural understanding possible? And specifically, what is a more effective approach for cross-cultural understanding? The answer lies in an analysis of two different models of cross-cultural understanding, that is, propositional and hermeneutic understanding. To begin with, the authors presents a linguistic interpretation of culture, i.e., a culture as a linguistically formulated and transmitted symbolic system with its conceptual core as a scheme of basic cultural presuppositions. Such a symbolic system is referred to as a cultural language. After exploring the essential role of cultural presuppositions in cross-cultural understanding, the authors discusses the traditional model of cross-cultural understanding, namely, the propositional model. Through critically examining the two popular versions of the propositional model, i.e., the projective approach and the adoptive approach to cross-cultural understanding, it is found that cross-cultural propositional understanding is doomed to failure. To move us beyond the absolutism-relativism trap embedded within propositional understanding, the authors first introduces and discusses Hans-Georg Gadamer's hermeneutic understanding, and then applies Hans-Georg Gadamer's hermeneutic model of understanding to cross-cultural understanding. It is finally concluded that cross-cultural understanding is essentially hermeneutic - including the case of cultural learning, not propositional. Therefore, cross-cultural understanding is hermeneutically possible.
\end{abstract}

\section{Introduction}

Substantial conceptual, ontological, or epistemic disparities between two radically distinct cultures can create serious impediments to cross-cultural understanding. In many 
cases, we often find that effective mutual understanding across two substantially distinct cultures is problematic and difficult; and in some cases, it seems in some measure unattainable. However, it would be a mistake to think that cross-cultural understanding is impossible. Any human culture is an open symbolic system, susceptible to modification, expansion, and evolution as well as open to human understanding. One can at least make an alien culture intelligible by cultural learning, no matter how remote it is from our own. Shared neurology and overlapping environments make it extremely likely that any member of one human culture can, with sufficient effort, always understand another culture by cultural learning. What we attempt to address here is not the question of whether cross-cultural understanding is possible; what we are primarily concerned with is a Kantian type of question: How is effective cross-cultural understanding possible if it is indeed possible?

To answer this question, we need to, first of all, clarify the conception of culture discussed in cross-cultural understanding. In section 2, we present a linguistic interpretation of culture, i.e., a culture as a linguistically formulated and transmitted symbolic system with its conceptual core as a scheme of basic cultural presuppositions, which we will refer to as a cultural language. Section 3 explores the essential role of cultural presuppositions in cross-cultural understanding. In section 4 , we discuss the traditional model of cross-cultural understanding, namely, the propositional model. After critically examining the two popular versions of the propositional model, i.e., the projective (absolutistic) approach and the adoptive (relativistic) approach to cross-cultural understanding, we find that cross-cultural propositional understanding is doomed to failure. To move us beyond the absolutism-relativism trap embedded within propositional understanding, we first introduce and discuss Hans-Georg Gadamer's hermeneutic understanding in section 5, and then apply Hans-Georg Gadamer's hermeneutic model of understanding to cross-cultural understanding in section 6 . It is finally concluded, in section 7, that cross-cultural understanding is essentially hermeneutic including the case of cultural learning, not propositional. Therefore, cross-cultural understanding is hermeneutically possible.

\section{Cultural Language}

What is human culture? Everyone seems to be able to recognize a culture when encountering it, but there is much disagreement when we attempt to define and clarify the conceptions of 'culture', ${ }^{1}$ culture as civilization, culture as worldview, culture as whole way of life, or culture as system of symbols, to mention only a few. This is not only due to the fact that culture, like any other comprehensive notion, defies any precise definition, but also because any given definition of culture is subject-relevant. Anthropologists, ethnologist, sociologists, cultural studies scholars, and philosophers may well emphasize different aspects of culture and approach culture from different perspectives. Fortunately, we have no need here to give a comprehensive dentition of culture; what we need instead is a topic specific notion of culture, namely, a conception of culture suitable for our discussion of cross-cultural understanding. Since symbols and meanings are basic components of understanding, following both Clifford Geertz's symbolic interpretation of culture and Hans-Georg Gadamer's linguistic notion of (cultural) tradition, the conception of culture to be adopted here is essentially symbolic and linguistic.

1 Alfred Kroeber and Clyke Kluckhohn compiled a list of 164 definitions of 'culture' in their 1952. 
The most influential aspect of Clifford Geertz's works has been his emphasis on the importance of symbols - of systems of meaning - as it relates to culture. For Geertz,

[T] he concept of culture I espouse ... is essentially a semiotic one. Believing with Max Weber, that man is an animal suspended in webs of significance he himself has spun, I take culture to be those webs, and the analysis of it to be therefore not an experimental science in search of law but an interpretative one in search of meaning. (Geertz 1973: 4-5)

Based on such a symbolic view of culture, we can regard a culture as a worldview or a whole way of life of a group of people which is nothing but a shared, internalized (taken-for-granted), learned, arbitrarily assigned symbolic system of meanings, including the behaviors, beliefs, values, and symbols that they accept generally without thinking about them, and that are passed along by communication and imitation from generation to the next. Because any symbolic meaning system involves relationships between the symbols and what they stand for that are conventional, not essential and universal, different human societies will inevitably agree upon different relationships and meanings which lead to distinct cultures.

Cultural symbols formulate and set the limits of cultural thought. Members of a culture rely on these symbols to frame their thoughts and expressions in intelligible terms. Symbols make culture possible, reproducible and readable. When we say that we do not understand the actions, both speech acts and behaviors, of people from an alien culture, we are acknowledging our 'lack of familiarity with the imaginative universe within which their acts are signs' (Geertz 1973: 12-13). Thus, cultural understanding is essentially the understanding of cultural symbols.

Although all cultural traits ranging from material artifacts (tools, house structures, art works, ceremonial objects, etc.), behavioral regularities (family relationships, economic exchanges, and legal sanctions, etc.), to abstract concepts and beliefs are cultural symbols, linguistic symbols or human languages are, as far as cross-cultural understanding is concerned, the most significant among all cultural symbols. It can be claimed further that culture is not just symbolic, but primarily linguistic in nature. As we read it, this is the real thrust of Hans-Georg Gadamer's notion of tradition. In fact, our conception of culture roughly corresponds to what Gadamer often refers to as 'tradition' or 'lifeworld'. For Gadamer, both our being-in-the-world and the-world-for-human-beings (the lifeworld or the world we live in) are primordially linguistic in nature due to the essential role of understanding in the formation of both our beings and our lifeworld (1989: 443). According to Martin Heidegger, understanding is ontological in the sense that it is not just one human faculty among others, but the primordial mode of being of Dasein. For Dasein, to be is to understand. Following Heidegger, Gadamer emphasizes further that understanding is universal: it underlies all human activities; nothing is, in principle, beyond understanding. Understanding is thus the primordial mode of human existence (our being-in-the-world). Furthermore, to Gadamer, 'all understanding is linguistic in character' (1970: 13).

'Language is not just one of man's possessions in the world, rather, on it depends the fact that man has a world at all. ... But this world is verbal in nature. ... Not only is the world world only insofar as it comes into language, but language, too, has its real being only in the fact that the world is presented in it.' (1989: 443) 
This is why, for Gadamer, 'tradition is essentially verbal in character' (1989: 389). Therefore, to Gadamer, cultural tradition is embodied in language, transmitted and handed down linguistically.

The thesis of the linguistic constitution of the world is the real thrust of Wilhelm v. Humboldt's idea that 'a language-view is a worldview'. However, Humboldt's concept of language is the linguist's notion of language, namely, particular types of natural languages as lexicon or grammar. For Gadamer, it is not by virtue of its linguistic form that a language is a worldview, but rather by virtue of what is embodied in the language. 'If every language is a view of the world, it is so not primarily because it is a particular type of language (in the way that linguists view language) but because of what is said or handed down in this language' (1989: 441). 'What constitutes the hermeneutical event proper is not language as language, whether as grammar or as lexicon; it consists in the coming into language of what has been said in the tradition' (1989: 463). For example, it is not Chinese language per se, as a natural language with its unique grammatical structure and lexicon, but rather the Chinese cultural tradition embodied in it, as handed down linguistically by the Chinese language, that constitutes the worldview of the Chinese. In other words, it is as embodying the happening of cultural tradition that a language is a worldview. To distinguish a language as the worldview of a culture from its natural language, we will refer to the former as cultural language.

Construed as such, a culture or cultural tradition is sedimented in its cultural language, in its lexicon, in its grammar, in its underlying presuppositions, and in its way of justification and reasoning, and is transmitted and handed down linguistically. Thus, our discussion of cross-cultural understanding will primarily focus on the understanding of cultural languages.

Cultural language is in fact what we call one type of presuppositional language elsewhere. ${ }^{2}$ To review the notion briefly here, by a presuppositional language we mean a comprehensive language which core statements presuppose a set of shared fundamental assumptions - contingent factual presuppositions - about the world perceived by a language community. An exemplar of presuppositional languages is scientific languages. ${ }^{3}$ It is not a novel idea nowadays that a scientific language is loaded with fundamental assumptions, such as the existence of phlogiston within the language of phlogiston theory, or the existence of absolute space and time for Newtonian physics. Those fundamental assumptions are absolute presuppositions as defined by R. G. Collingwood: they are unquestionable within a certain domain of inquiry. In this sense, an absolute presupposition is not even a proposition since its falsity is unimaginable within a certain language community; it not asserted, but made or presupposed, i.e., its truth is taken for granted (Collingwood 1940: 32). We contended that those absolute presuppositions of a presuppositional language are universally true when perceived within the language community in the sense that denial of them signifies a complete breakdown of informative use of the language.

As a type of presuppositional language, the conceptual core of any cultural language consists in a set of basic cultural assumptions, such as the yin-yang cosmology in traditional Chinese culture. Those cultural assumptions are actually absolute presupposi-

2 See Wang 2002 and 2003.

3 A scientific language, following the convention in the discipline of philosophy of science, refers to a theoretical language employed to formulate a comprehensive scientific theory, such as Newton's physics, Aristotelian physics, Einstein's relativity theory, traditional Chinese medical theory. 
tions within certain cultural contexts. I will refer to a set of absolute cultural presuppositions of a cultural language as its culture-scheme. Arguably, the content of a culture-scheme changes with a specific culture. To unearth the culture-scheme of a specific culture, we have to analyze that cultural language individually. In the following section, for the purpose of illustration, I will discuss the cultural-scheme of pre-modern Chinese culture briefly.

To analyze pre-modern Chinese cultural tradition, the Yin-Yang doctrine is the best place to start. In Chinese philosophy, the Yin-Yang doctrine sounds very simple but its influence has been extensive. It is not an exaggeration to say that no aspect of Chinese culture, whether cosmology, social, political, and legal systems, religion and moral systems, art, rituals, and customs, has escaped its influence. In simple terms, the doctrine claims that all things and events in the universe are produced and controlled by two forces or principles, namely, the yin and the yang. The Yin-Yang doctrine is associated with the doctrine of Five Elements: Metal, Wood, Water, Fire, and Earth. Everything is made of the five different elements (or processes). The Five Elements are not only an elaboration of the Yin-Yang idea, but actually add the important concept of rotation, i.e., things succeed one another as the Five Elements take their turns. During the Warring States period (403 - 222 B.C.), the ancient Yin-Yang School developed and transformed the Yin-Yang doctrine into the first unified system of cosmology in Chinese civilization: the universe was conceived of as a well-coordinated system and a process of self-transformation in which everything is related to everything else. The Yin-Yang School and its cosmology exerted a profound influence upon the succeeding development of the Chinese cultural tradition. Turning to the Han dynasty (206 B.C. - 220 A.D.), the Yin-Yang doctrine came to be almost completely amalgamated with Confucianism and became the mainstream of pre-modern Chinese cultural tradition.

We can thus identify four cultural presuppositions that constitute the core of pre-modern Chinese cultural tradition: (C1) The Yin-Yang doctrine; (C2) The Five-Element doctrine; (C3) The principle of pre-established harmony: there exist mutual correlations among things in general and the correspondence or mutual influence between human affairs and Nature in particular; (C4) The doctrine of constant transformation: within the organic structure of the universe, everything undergoes constant transformation.

More significantly, along with the rise and development of the pre-modern Chinese yin-yang cosmology, a unique pre-modern Chinese mode of thinking evolved during the same historical process. It can be best characterized by the specific way of understanding the world perceived within pre-modern Chinese cultural tradition. According to this mode of thinking, the world is composed of and operated by the yin-yang and the Five Elements. Human beings, holding the most exalted position in it, become attuned to the world to such an extent that they became a shadow in brief of the universe, and are melted into it. Because of such a close relationship with the universe, the ancient Chinese did not treat the surrounding world as the object outside that human beings could love, rebel against, or control. They appreciate the blessing (associated with the yang part of the universe) and accept punishing (associated with the yin part of the universe) from T'ien and Earth. This attitude toward the world and the close correlation between the universe and human affairs shows that for the ancient Chinese, understanding the universe was intertwined with achieving attunement with it. Understanding and attunement are related so closely that attunement eventually be- 
came a necessary condition of understanding. During its historical development, the association of attunement and understanding had been elevated to a position of high importance and gradually incorporated into the mainstream values of the Chinese culture. Consequently, it eventually became institutionalized as the dominant mode of thinking within pre-modern Chinese cultural tradition. Actually, the intertwining of attunement and understanding has been a persistent theme presented in almost all schools of pre-modern Chinese philosophies and recurring throughout the Chinese intellectual tradition (Wong 1989: 150-1).

Sinologists call this unique Chinese mode of thinking 'associated thinking', which is actually a distinctive logical form of rational justification or the very form of reasoning. The rule not only determines what facts count as evidence for justification (in what ways they count and the weight of evidence in support of propositions), but also determines what states of affairs count as permissible facts. For example, according to this mode of reasoning, a specific interaction between the yin-yang parts in the human body and the yin-yang forces in Heaven counts as a possible fact. Many symptoms can be attributed to the associations between natural forces and changes-which represent the yin or the yang principles of the universe -and the yin-yang parts of the human body that are supposed to correspond to the former. For instance, according to Han Confucians, when Heaven is about to make rain (representing the yin) fall, people feel sleepy. This is because when the yin force in Heaven and Earth begins to dominate, the yin in the human body takes over. The association between the yin and rain causes increased sleepiness among people.

\section{The Role of Cultural-Schemes in Cross-Cultural Understanding}

A cultural language is laden with some specific cosmology, embodies a mode of reasoning, and reflects a form of life. The conceptual richness of a cultural language determines the depth and inclusiveness of understanding it. A cultural language is fully intelligible; its purported justification is adequately understood only if its underlying cultural-scheme is fully comprehended. Any interpreter who fails to do so cannot see the 'point' of the language and cannot fully understand it. Consequently, cross-cultural understanding cannot be achieved. To illustrate, let us consider the following two statements, one from Chinese medical theory within pre-modern Chinese cultural tradition, and the other from phlogiston theory within Western cultural tradition:

(P1) The association of the yin and rain makes people sleepy.

(P2) Element $a$ contains more phlogiston than element $b$.

Now consider Dr. Smith who is educated within contemporary Western cultural and scientific tradition. Suppose that he is familiar neither with phlogiston theory nor with Chinese medical theory and its underlying pre-modern Chinese mode of reasoning. Is Dr. Smith able to understand P1 or P2?

We find that although both $P 1$ and $P 2$ are unintelligible to Dr. Smith, it is important to make a distinction between the two. An old theory within the same cultural tradition may be forgotten, but can still be made intelligible to the modern reader who is willing to spend the time relearning it. In contrast, an alien cultural language, especially when embodied within a cultural tradition which is substantially different from the interpreter's, indicates such a radically disparate mode of thinking as to require something far more complicated than mere learning of the language itself. In order to understand 
it, one has to learn the whole form of life behind it (with the mode of reasoning as its cores).

The primary cause for why Dr. Smith fails to understand $P 2$ lies in the meaningless term 'phlogiston'. As long as he learns the meaning of the term and the corresponding existential assumption (the existence of phlogiston), he is able to understand P2. Although Dr. Smith does not believe there is such a substance as phlogiston, he can work it out and understand the point of what Joseph Priestley was saying when presenting his phlogiston theory. This is mainly because Priestley's phlogiston theory, lying within the same cultural tradition as modern science, is conceptually recognizable to Dr. Smith.

In contrast, Dr. Smith's failure of understanding $P 1$ does not just lie in a meaningless term 'yin'. He can understand the meaning of 'yin' by being given a plain definition. But even if he could make sense of $P 1$ (in the sense that it does not involve any meaningless term and the terms are not combined in any illegitimate way), he would still be left in a fog. What is the point of what is being presented or argued for by $P 1$ ? Or what is the thought that $P 1$ expresses? To know the point of what is being said by $P 1$, Dr. Smith has to know the proper contexts in which $P 1$ can be used to say something true or false. But such contexts are not conceptually recognizable to him, for he does not comprehend the conceptual framework (consisting of the pre-modern Chinese mode of reasoning and its underlying yin-yang cosmology) within which these possible contexts are constructed. To grasp the thought expressed by P1, Dr. Smith needs to comprehend the pre-modern Chinese mode of reasoning that are central to the thought and presupposed by the proposition expressed by $P 1$.

Unfortunately, it is the pre-modern Chinese mode of reasoning that is totally alien and scarcely comprehensible to Dr. Smith. As we have argued, the goal of attunement to nature was so highly valued in the pre-modern Chinese culture that it became a necessary condition of understanding and rational justification. Then it is possible that what ancient Chinese thought to be rationally justifiable and perfectly intelligible is not at all rationally justifiable and intelligible in a cultural tradition that severs the connection between understanding and attunement. This is what actually happens when Dr. Smith encounters P1. As Charles Taylor points out, the world for the European intellectual tradition ceased to be a possible object of attunement after the rise of modern science. Instead, the world became alienated from human beings and became the object of investigation, experiment, and control. The original connection between understanding and attunement was severed, and was dismissed as mere projection onto the world order of things human beings find meaningful (Taylor 1982). Therefore, the pre-modern Chinese mode of reasoning, which values attunement so highly, is totally alien to the modern Westerner and hard to understand. This explains why many substantial sentences of traditional Chinese medical theory such as $P 1$ sound so strange to Dr. Smith that he cannot fully grasp them.

Theoretically, 'what a sentence of an alien language means' can be used to refer either to the meanings of the words used in the sentence, or to the thought expressed by it. To understand what a sentence of an alien language means is not just to know the meanings of its words. To effectively understand a sentence of an alien language is not just to simply make sense of it, but rather to grasp the thought expressed by it. To know the thought expressed by a sentence, it is necessary to know that it is assertable or that it has a point, and to know what it asserts or what its point is. If a sentence is comprehensible to an interpreter, she/he has to understand the point of what is being 
said, being presented, or being argued for. Whether or not a sentence of a cultural language, when considered within the context of the interpreter's own cultural language, can be used to make an assertion is language-dependent. More precisely, it is determined by the culture-scheme of the language. A sentence that is apparently the same could be used to assert something or have a point within the context of one cultural language but without a point in a rival one. This establishes the fact that in order to capture the point of what is being said by a sentence of an alien cultural language, it is necessary to comprehend its culture-scheme. In conclusion, a cultural language is intelligible to the interpreter only if its culture-scheme is conceptually recognized and comprehended.

\section{The Propositional Model of Cross-Cultural Understanding}

Presumably, to understand a language is to comprehend the meanings of its sentences. But what is supposed to be the meaning to be comprehended? Following the convention, we can identify three structural components of the meaning of an utterance: its propositional content, its expressive content, and its illocutionary content. A complete understanding of a linguistic expression should involve all those three aspects. However, since the propositional content of a sentence is the semantic foundation upon which the other dimensions of its meaning depends, to understand a sentence could mean to comprehend its propositional content, the thought expressed, or its literal meaning (the meaning determined by the linguistic conventions of a language). We will refer to this notion of understanding as propositional understanding.

Propositional understanding is founded on the monological model of meaning, according to which the meaning of a text is determined by the author's intention alone, along with the necessary linguistic conventions of the author's language. The text is self-enclosed, its meaning is self-contained, and hence its propositional content is self-determinate, simply there to be discovered, independent of the interpreter and the communication process between the author and the interpreter. The aim of understanding is comprehension, namely, to grasp the original meanings or the fixed propositional contents of a text.

It is argued in section 3 that the interpreter can effectively understand a cultural language only if she/he is able to identify and comprehend its culture-scheme. Apparently, culture-schemes are culture-dependent. Hence cross-cultural understanding is culture-dependent. Just as it is not useful to ask whether a sentence itself is true or false but only whether a specific use of it within a linguistic context is true or false, so it is not useful to ask whether or not a sentence in isolation is meaningful. We can only ask whether it, when considered within the context of a specific language, is meaningful, and what its meaning is. Therefore, the core sentences of a cultural language that are meaningful in the context of its own might not be fully understood when considered within the context of some incompatible cultural languages (languages with incompatible culture-schemes).

The language-dependent feature of cross-cultural understanding has a significant impact on cross-language understanding. When two disparate cultural communities confront one another, each with its own culture-scheme, but lacking knowledge of the other, those who are trapped in the mode of propositional understanding often fall into the two opposite temptations. On one extreme, they tend to adopt the projective approach to cross-cultural understanding, i.e., to approach the other by imposing, reading into, or projecting the categories, beliefs, mode of reasoning embodied in one's own 
cultural language upon the other. On the other extreme, they are likely to take the adoptive approach, namely, 'going native to be other' by putting oneself into the alien's skin, or jumping into the stream of the other's consciousness.

Following the projective approach, for lack of an alternative, the interpreter is tempted to understand an alien culture as she/he would if it had occurred in her/his own cultural tradition, in abstraction from the relevant cultural tradition of the other's. This is a phenomenon frequently encountered by anthropologists when they encounter an alien culture. A hidden assumption lurks behind the projective approach: others are basically like us with shared cultural-schemes. This is a form of absolutism in cross-cultural understanding, a basic conviction that there is or must be some permanent, ahistorical, culture-transcendent matrix or framework to which one can ultimately appeal in determining the nature of rationality, intelligibility, truth, reality, and morality.

When the culture-scheme of an alien cultural language is compatible with that of the interpreter's own, the projective approach can proceed without much difficulty. The interpreter is able to understand the other cultural language since she/he can recognize its culture-scheme by way of analogy. However, if the culture-schemes of two cultural languages were incompatible, projecting the culture-scheme of the interpreter's own cultural language upon an alien cultural language would suspend or distort the culture-scheme of the latter. Suspending a cultural language's culture-scheme would suspend all empirical contents of meaningful statements of the language. By distorting them the interpreter puts the original meaningful statements out of their appropriate contexts and hence causes them to lose their original meanings. Either way prevents recognition and comprehension of the culture-scheme of the alien language. Lack of knowledge of the culture-scheme of an alien cultural language is sufficient to preclude effective understanding of the language. From each point of view certain of the key concepts and core statements of the other, just because they are presented apart from the cultural context constituted by its own culture-scheme from which they draw their conceptual life, will necessarily appear without context, lack justification, and hence become meaningless and unintelligible. Therefore, in an abnormal discourse, that is, a discourse in which the culture-schemes of two cultural languages in exchange are incompatible, the projective approach to cross-cultural understanding is doomed to failure.

The failure of the projective approach tempts many into taking the adoptive approach to cross-cultural understanding. Compared with the projective approach that is a third-person, objectivist approach, the latter is a first-person, phenomenological approach to understanding. This temptation is very strong in the field of anthropology. One general problem that has been exercised in methodological discussion in anthropology is this: How is anthropological knowledge of the way natives think, feel, and perceive possible? As many believe, anthropological understanding stems from some sort of extraordinary sensibility, an almost preternatural capacity to think, feel, and perceive like natives. It is believed that rather than attempt to place the experience of natives within the framework of our own, we must, if we are to achieve understanding, set our own framework aside and view their experiences within their own framework.

Perhaps the two most provocative versions of the adoptive approach are Peter Winch's social-cultural relativism and Benjamin Whorf's linguistic-cultural relativism. Winch finds that many influential studies of primitive societies have gone astray because they are frequently insensitive to the different 'points' and 'meaning' of the 
other's activities and beliefs that would reveal to us 'different possibilities of making sense of human life.' To understand a society or culture is, for Winch, to make it intelligible. But the notion of intelligibility is context-dependent. Each society or culture has its own criterion of rationality and intelligibility. We cannot say which one is better. The criterion is formed and defined within a specific form of life. A form of life, as Wittgenstein defines and argues, is the given that we have to accept. Forms of life endorsed in different cultures may be so radically different from each other that in order to understand alien or primitive societies we not only have to bracket our prejudices and biases, but also have to suspend our own standards and criteria of rationality and intelligibility. Therefore, to understand an alien or a primitive society it is necessary to understand it somehow from within, on its own terms and by its own standards (Winch 1958: 18, 35, 39, 40, 107).

Based on his extensive research on the language of the American Hopi, Benjamin Whorf (1956) argues that the Hopi language is embedded with (or, simply is) a metaphysics and a cosmology radically different from those found in European languages. When a linguist 'imposes his own ontology and linguistic pattern on the native,' he fails to understand the Hopi speaker. The Hopi grammar, with no verb tenses as we know them and with no reference to kinetic rather than dynamic motion, is not an alternative way to express Western Newtonian time and space. It is an alternative way of thinking of and understanding the basic elements of reality. Although pragmatically equivalent English expressions can be 'recast' in Hopi terms, this should not be confused with understanding. To truly understand Hopi, one has to try to think in the Hopi way, or at least to achieve relative consonance with the system underlying the Hopi view of the universe.

As a solution to the failure of cross-cultural understanding in abnormal discourse, the adoptive approach faces many problems. Gadamer puts it best: 'it is neither possible, necessary, nor desirable that we put ourselves within brackets' (1979: 151-2). Just how can one jump into the stream of the other's experience? Gadamer reminds us that one is ontologically grounded in one's own tradition, culture, and language since one's tradition, culture, and language are not contingent properties of an abstract self, but are constitutive of one's being. One always belongs to a certain tradition, culture, and language before it belongs to one. One simply cannot place oneself in the other tradition without losing oneself. Therefore it is impossible for one to leave behind one's own tradition and to place oneself in other traditions. Anthropologist Clifford Geertz concurs: 'The ethnographer does not, and in we opinion, largely cannot, perceive what his informants perceive. What he perceives - and that uncertainly enough - is what they perceive "with", or "by means of", or "through" or whatever word one may choose' (Geertz 1979: 228). No matter how accurate one can be about what one's informants are 'really like', it comes from the ethnographer's own experience, not from the informants' experience.

The champion of the adoptive approach could maintain that even if one accepts as an empirical fact that one cannot sufficiently attain the ideal of leaving oneself behind, this would still be a legitimate ideal that one should strive to reach as far as possible. Gadamer argues further that the adoptive approach is not simply impossible, unnecessary, but also undesirable, and even detrimental, for achieving cross-cultural understanding. As it will be explored in the next section, according to Gadamer's hermeneutic understanding, not only do all understandings inevitably involve some prejudices, but also the understanding of the alien cultural tradition is only possible based on pre- 
judgments provided by one's own cultural tradition. The other can only speak to one in one's own tradition. 'To interpret means precisely to bring one's own preconceptions into play so that the text's meaning can really be made to speak for us' (Gadamer 1989: 397).

We have seen so far that the propositional model of cross-cultural understanding fails to understand an alien cultural language in two contrastive ways: by 'going native' or by projecting one's culture-scheme onto the others. In either case, one cannot achieve the goal of cross-cultural understanding, learning of insights, and reaching agreement. Gadamer drives home the point that propositional understanding is doomed to failure in abnormal discourse in the following:

There are no propositions which can be understood exclusively with respect to the content that they present, if one wants to understand them in their truth. ... Every proposition has presuppositions that it does not express. Only those who think with these presuppositions can really assess the truth of a proposition. I maintain, then, that the ultimate logical form of the presuppositions that motivate every proposition is the question. (Gadamer 1986: 226; first italics are mine)

Put into our terminology, Gadamer is actually arguing that proper propositional understanding of an alien cultural language depends on the grasp of its culture-scheme. In abnormal discourse, if interpreters cannot comprehend the culture-scheme of an alien cultural language, they cannot grasp the propositions expressed by the sentences of the language. Consequently, the propositional understanding of the alien fails. The best alternative in this situation is to work out the culture-scheme of the alien cultural language by engaging in a dialogue to ask questions, to hypothesize the alien way of thinking, to make comparison between their own language and the alien's. To do this, the interpreters inevitably become involved in the hermeneutic circle between their own language and the alien's. This is where Gadamer's notion of hermeneutic understanding comes into play, which is promising to be an alternative to avoid antithetical poles of the projective and the adoptive approaches to cross-cultural understanding in order to achieve authentic understanding in abnormal discourse. This is what we want to turn to next.

\section{Gadamer on Hermeneutic Understanding}

Gadamer's abiding concern has been to answer the question, 'How is understanding possible?' through exploring fundamental conditions of understanding. In the following discussion, we will focus only on those aspects of Gadamer's philosophic hermeneutics relevant to our topic, that is, how to reach cross-cultural understanding between two radically distinct cultures.

Coming to an understanding through conversation: the dialogical model of meaning

For Gadamer, the substance of hermeneutic understanding is revealed through Plato's insight on Socratic dialogue, that is, the hermeneutic priority of questioning in all experience, all knowledge, and discourse. With R. D. Collingwood, Gadamer contends that all understanding begins with questions. We can understand a text only when we have understood the question to which it is an answer. Such a close relation between questioning and understanding is "what gives the hermeneutic experience its true dimension' (Gadamer 1989: 374). The fundamental nature of questioning is its open- 
ness. One's questioning of a thing to be understood opens up the undetermined possibilities of its meaning. This is the reason why understanding is always more than merely re-creating the author's intention or the text's original meaning. What is meaningful passes into one's own thinking on the subject in the context of one's own horizon. The fullness of meaning is constantly in the process of being redefined and can be realized only during the dialectic of question and answer. Such a dialectic interplay of question and answer, which leads to genuine understanding, is actually a reciprocal relationship of the same kind as conversation. As such, genuine understanding turns out to be a process of coming to an understanding through conversation.

This conversation model of understanding is in sharp contrast to the traditional binary mode of understanding, i.e., the propositional model, which is based on the monological model of meaning: the interpreter understands something unilaterally since she/he has no part in meaning creation and what is to be understood cannot speak back. In contrast, Gadamer pushes toward a tripartite model of understanding: one person comes to an understanding with another person about a subject matter through conversation. In essence, Gadamer's hermeneutic understanding subscribes to what we will call the dialogical model of meaning. According to this model, as in a conversation, a partner does not receive completed meanings from another partner. Meanings are co-created and refined as both interlocutors emerge and engage in a live conversation through questioning and answering. Just as the meaning of a work of art can only be contextualized and completed through a dynamic interaction between the work of art and the spectator who shares in it, the meaning of a text is not simply there waiting to be discovered. Instead, the meanings of all texts are actualized only when they are understood. Therefore, 'understanding must be conceived as a part of the process of the coming into being of meaning, in which the significance of all statements those of art and those of everything else that has been transmitted - is formed and made complete' (Gadamer 1975: 146). ${ }^{4}$

The role of prejudices in understanding

Gadamer's dialogical model of meaning has a direct impact on the role of the interpreter's own tradition in understanding. If the interpreter's participation in understanding is part of the making of the meaning, it is an illusion to think that the interpreter can eliminate her/his anticipatory prejudgments or prejudices, to somehow abstract her/himself from her/his own historical context or cultural tradition in order to enter into the minds of the others. Ontologically, our prejudices determine our beings. But these prejudices are not of our own making, nor an act of subjectivity, but are determined by the 'commonality which binds us to the tradition' (Gadamer 1989: 293). As Gadamer sees it, we belong to a tradition before it belongs to us. A tradition is handed down to us. Belonging to a tradition is standing in a happening of tradition. It is our tradition, through its sedimentations as prejudgments, that constitutes what we are in the process of becoming.

As a precondition of understanding, our prejudices and fore-understanding are what make our initial understanding possible. Whatever is understood is understood on the basis of a pre-understanding or anticipation of meaning (fore-meaning). Since our prejudices are determined by our tradition, wherever there is understanding there is pre-understanding determined by the happening of tradition in which we stand. Then,

4 As the bibliography indicates, we refer to two different translations of Gadamer's Truth and Method for more accuracy with the original text. 
what is the mechanism through which a tradition informs understanding? It is through language. Understanding is a linguistic activity and is discursive, and as such is subject to the traditions sedimented in language use. Since we are 'thrown into' a tradition, the projections of meaning that make understanding possible are 'thrown' projections. The projection of meaning is not so much the act of an individual interpreter but the act of a member of a historically and culturally conditioned language community. Thus, as determined by tradition through commonly shared language, understanding is not and cannot be arbitrary. On the contrary, 'understanding reaches its full potential only when the fore-meanings that it begins with are not arbitrary' (Gadamer 1989: 267).

To claim that our being and our understanding are conditioned and shaped by our tradition in terms of our prejudices does not necessarily commit us to Rudolf Carnap's 'Myth of Framework' - that we are enclosed within a wall of fixed prejudices which isolate us from others. For Gadamer, 'prejudices are biases of openness to the world' and to others from different traditions. They are by nature an open system - always anticipatory, always subject to transformation, and always future-oriented. To see how prejudices can evolve during understanding and how we can reach out to others in terms of our own prejudices, we need to see what happens when we encounter others.

\section{The hermeneutic circle}

For Gadamer, hermeneutic understanding is the dialectical interplay between interpreters' fore-structures and the text to be understood. On the one hand, although interpreters have to rely on their prejudices in any understanding, not all prejudices are conducive to fostering understanding. Hence they must be 'on guard against arbitrary fancies and the limitations imposed by imperceptible habits of thought' which lead to misunderstanding (Gadamer 1989: 266). Interpreters must be guided by the 'things in themselves' and keep their gaze fixed on the texts to be understood; they must be open minded, to listen to, to share, to participate with them so the texts can 'speak to' them. On the other hand, openness and receptiveness to the 'things in themselves' are possible only in terms of 'justified prejudices' that open and guide them to other's languages, experiences, and traditions. This requires that interpreters be able to identify unjustified prejudices, revise them, and replace them with 'more suitable ones'. Unfortunately, interpreters cannot separate in advance justified ('true' or 'enabling') prejudices that enable understanding from unjustified ('false' or 'blind') ones that lead to misunderstanding. Rather, this separation must take place in the very process of understanding through the interplay between the unjustified prejudices and the 'things in themselves'. Therefore, hermeneutic understanding involves constant movement from less suitable prejudices to more suitable ones.

How can we know whether we have reached a correct understanding and what exactly counts as true or legitimate prejudices that promote correct understanding? The answer seems to lie in the 'anticipation of completeness' through the hermeneutic circle. Only what really constitutes a coherent unity of meanings is acceptable and should be our goal of understanding. In seeking to understand a text, we first project tentative fore-meanings for the text as a whole (the whole). But those fore-meanings have to be revised in light of attention to the details of the text (the part). Through constant negotiation and argumentation between our evolving fore-meanings (the whole) and the text itself (the part), we move toward 'the harmony of all the details with the whole'. Our projected fore-meanings are confirmed by the 'thing in itself' of the text when a 
unity of meaning (the real, true meaning) is borne out. A true or legitimate prejudice is one that leads to a coherent understanding of the text when we attend to the details of the text in light of it, or which survives engagement with the text by resulting in a coherent lifeworld - a coherent interconnection of meanings, beliefs, values, and norms. Accordingly, an understanding is correct or warranted when it reveals the true meaning of what is to be understood (Gadamer 1989: 291).

\section{Fusion of horizons}

If to understand means to come to an understanding with each other through conversation, then the further question is: What is the primary purpose of conversation? For Gadamer, it is to reach substantive agreement with one another on some subject matter. To do so, one cannot either impose one's own tradition onto the other or place oneself into the other's tradition with the sole purpose of knowing 'objectively' the other's tradition. Genuine conversation is not assimilation, neither to make the other like one nor to make one like the other; since in both cases, one has stopped trying to reach a genuine agreement with one another. In contrast, to reach genuine agreement through authentic conversation, 'both partners are trying to recognize the full values of what is alien and opposed to them. If this happens mutually, and each of the partners, while simultaneously holding on to his own arguments, weights the counterarguments, it is possible to achieve ... a common diction and a common dictum' (Gadamer 1989: 387). The process of reaching such an agreement is what Gadamer calls the process of fusing horizons.

By horizon, Gadamer means 'the range of vision that includes everything that can be seen from a particular vantage point' (1989: 302). One's particular horizon is formed by one's particular tradition. Ultimately it is a whole historical lifeworld - the world in which one lives out one's life, a web of meanings, beliefs, values, and norms. A horizon is limited and finite; but it also is essentially an open system, open to self-transformation and open to being understood. To have a horizon means not being limited to what is nearby but being able to see beyond it.

When one tries to understand a horizon other than one's own, especially an alien horizon from an alien tradition, one cannot simply replace one's own horizon with the alien's. The placing of oneself in an alien horizon is not and cannot be a case of leaving one's own horizon behind. One has to place oneself in the other horizon, and oneself is an ontological being with its essence determined by one's own horizon. One can experience the genuine otherness only by placing oneself existing within one's own horizon, as a filter to separate the oneness from the otherness, in the other's horizon. The genuine otherness can be revealed to one only against the background of one's oneness. Therefore, for Gadamer, the understanding of the other can be achieved by a 'fusion of horizons', a fusion between the horizons of the interpreter's and the interpreted, whereby the interpreter's horizon is enlarged and enriched in terms of the engagement with the horizon of the interpreted.

\section{The Hermeneutic Model of Cross-Cultural Understanding}

The relevance of Gadamer's discussion of hermeneutic understanding to our question at hand is palpable: How is cross-cultural understanding possible? In fact, as we see it, Gadamer's philosophic hermeneutics provides a new model of cross-cultural understanding which moves us beyond the propositional model of cross-cultural understand- 
ing and the dilemma of absolutism and relativism in cross-cultural understanding. Let us be more specific.

The contact point between Gadamer's linguistically formulated and transmitted tradition as worldview and our concept of cultural language has become evident. It would not be too much of an exaggeration to claim that our concept of cultural language is, roughly, a linguistic counterpart of Gadamer's notion of tradition, which itself is linguistically formed and transmitted. Just as there are multiple cultural languages, there exist different traditions, each of which corresponds to a linguistically constituted world or worldview and has its own unique path of development. A language community situated in a particular cultural tradition sees the world differently from another language community belonging to a different cultural tradition. Distinct traditions or language-worlds might be in conflict with one another, which puts mutual understanding between them at risk. The similarity between the concepts of cultural language and tradition becomes more striking if we consider the similar roles of the cultural-schemes of a cultural language and the prejudices of a tradition in understanding. Pre-judices and pre-judgments conditioned by a tradition are actually pre-suppositions of a cultural language. Of course, Gadamer's notion of prejudice is broader than that of cultural-scheme. But we think Gadamer would agree that the cultural schemes we have identified are clearly prejudices that shape one's worldview and are preconditions for cross-tradition understanding.

Now, let us see what happens when we try to understand an alien cultural language or language-world from the perspective of Gadamer's hermeneutics. To begin with, we are always ontologically situated in a cultural tradition, which is, as a form of life, articulated in our own home cultural language. From this given horizon - the existential state of the language community - the language community forms a specific cultural scheme, including a cosmology or universal principles about the world surrounding it and a mode of reasoning. When confronting an unfamiliar alien cultural language or language-world, it is natural for us to project these prejudgments or cultural presuppositions from our home cultural language onto the other. The projection is not in the first place a matter of choice. Rather, we are 'thrown' into it. All understanding is projective. Contrary to the relativistic adoptive approach to cross-cultural understanding,

[T] he fact that our experience of the world is bound to language does not imply an exclusiveness of perspectives. If, by entering foreign language-worlds, we overcome the prejudices and limitations of our previous experience of the world, this does not mean that we leave and negate our own world. Like travelers, we return home with new experiences. Even if we emigrate and never return, we still can never wholly forget. (1989: 448)

Instead, the prejudgments or cultural presuppositions from our own cultural language should be considered almost like transcendental 'conditions' or the springboard of understanding from which we can reach out to the other cultural language. In this sense, our own cultural language is not a restriction but the very principle of understanding. Therefore, we do not need to (and cannot either) bracket or forget our own cultural language in order to understand the other's.

However, this by no means restricts us to the absolutistic projective approach to cross-cultural understanding. On the one hand, we cannot rely blindly on the prejudgments or cultural presuppositions of our own cultural language, and take the projective 
approach from our own cultural language as the proper one. In order to understand an alien cultural language, we must make our own cultural presuppositions transparent so that we can appreciate precisely the otherness without concealing the proper meaning of the other cultural language by allowing our unelucidated prejudices to distort it. To reveal self-reflectively the cultural presuppositions of our own cultural language, it is necessary to allow otherness of an alien cultural language to be disclosed. Only after we are conscious of the cultural presuppositions embedded within our own cultural language, can we allow the other cultural language to speak for itself, to reveal its proper meaning. On the other hand, only in confrontation with an alien cultural language and its cultural presuppositions, can we hope to get beyond the limits of our present cultural horizon. It is precisely in and through the understanding of an alien cultural language and a realization of how different others are from our own that we can come to a more sensitive and critical understanding of our own cultural language and of those cultural presuppositions or prejudices that may lie hidden from us. Self-consciousness is always relative to consciousness of otherness and alienness. To understand an alien cultural language, we must participate or share in it, listen to it, open ourselves to what the language is saying, and allow it to speak to us.

The above dialectical interplay between the understanding of our own cultural language and the understanding of an alien cultural language is Gadamer's hermeneutic circle of understanding in action. Whilst we must not allow ourselves to be blinded by the prejudgments or cultural presuppositions coming with our own cultural language; otherwise we will be unable to open ourselves to the other and allow the other to speak to us. Neither should we bracket all the prejudgments or cultural presuppositions of our own cultural language, nor should we jump into the stream of the other's experience. It is only the play of these cultural presuppositions that allows us to engage in the process of understanding, to reach out to the other, and to capture the meaning of an alien cultural language. Therefore, mutual understanding between two distinct cultures necessarily involves a constant movement back and forth between one cultural language and the other cultural language. It would eventually reach a fusion of the two cultural horizons which can serve as a moving common ground between the two cultures. Of course, all those have to proceed during the process of constant cultural dialogue or conversation.

However, our hermeneutic model of understanding seems to face two potential objections from the advocates of the propositional model. To see further the advantages of the hermeneutic model of cross-cultural understanding over the propositional model, we need to address these two potential objections.

One objection has something to do with the epistemic status of hermeneutic understanding in comparison with the propositional understanding due to the interpretative character of the former. As we have mentioned, Gadamer's notion of hermeneutic understanding arises as a rebellion against the traditional notion of propositional understanding. Heidegger considers propositional understanding to be secondary and derivative from universal hermeneutic understanding. Like Heidegger, Gadamer considers the 'construction of logic on the basis of the proposition' to be one of the 'most fateful decisions of Western culture' (1986: 195) since 'language is most itself not in propositions but in dialogue' (1985: 98). Against the primacy of the notion of propositional understanding, which assumes a self-contained propositional content for each sentence, the hermeneutic approach adopts the dialogical model of meaning. An interpreter's understanding of what a speaker's utterance is saying becomes an activity of 
the interpreter's participation in the reformation and enrichment of its meaning, the engagement between the speaker's and the interpreter's traditions or a fusion of horizons, assimilating what is said to the point that it becomes the interpreter's own, and ultimately a dialogue between the interpreter and the speaker.

Consequently, the process of hermeneutic understanding involves a complex process of re-interpretative reconstruction on the part of the interpreter, which is not just purely reproductive, but also a productive activity. The advocate of propositional understanding may suspect that hermeneutic understanding turns out to be what we usually call the process of interpretation. But interpretation is supposed to be a different process from understanding. Understanding is a unilateral process in which the subjectivity of the interpreter is not supposed to be part of the process in the ideal situation. This is why we always strive for a value-free, objective understanding with a goal to attain some final adequate understanding. Propositional understanding is, if applied properly, supposed to be such an objective understanding. In contrast, interpretation is less stringent regarding understanding. Interpretation is a bilateral process in which the interpreter comes to an interpretation through the interplay between the interpreter's own fore-knowledge and what is to be interpreted. Since both the fore-knowledge of the interpreter and the context in which an interpretation takes place can change, we can never have a final interpretation. Clearly, the advocate of propositional understanding would continue, Gadamer confuses understanding with interpretation. However, understanding is not interpretation. So the hermeneutic model of cross-cultural understanding, no matter how effective it seems to be for cross-cultural communication, cannot achieve full cross-cultural understanding.

The critic is right on the point that hermeneutic understanding is interpretation, more precisely, interpretative understanding; but the critic is wrong to separate understanding from interpretation as two independent processes. Actually, in the early tradition of hermeneutics, which seeks to draw a rigorous distinction between understanding and interpretation, there is first a pure, objective understanding of meaning existing in the text, which is free from all prejudices and not contaminated by subjective interpretation. Interpretation is supposed to be a supplement to understanding. In bold new contrast to this tradition, Heidegger and Gadamer argue that there are no essential differences between understanding and interpretation. 'Interpretation is not an occasional, post facto supplement to understanding; rather, understanding is always interpretation, and hence interpretation is the explicit form of understanding. In accordance with this insight, interpretative language and concepts were recognized as belonging to the inner structure of understanding' (Gadamer 1989: 307). Thus, understanding and interpretation are internally related or fused, both of which compose one unified process. Every act of understanding, including propositional understanding, involves interpretation, and every act of interpretation involves understanding. Since we are always understanding in light of our anticipatory prejudgments determined by the effective historical situation in which we live, we always take ourselves along whenever we understand. Therefore, all understanding is interpretative understanding. Genuine understanding is hermeneutic understanding, not propositional understanding. This is especially true in the case of cross-cultural understanding.

Another potential objection to our hermeneutic model of cross-cultural understanding deals with the case of cultural learning. The critic may ask: Can there be a better way to understand a cultural language than through learning process by immersing ourselves in the culture? We know that the most efficient way for the anthropologist to 
understand the native encountered is to learn the native's language by living in the community. The same should be true for our would-be interpreter who faces an alien cultural language. Although to understand some radically disparate cultural language, one has to learn it in a wholesale manner (learn the language together with the underlying mode of reasoning, the cosmology, the categorical framework, and other cultural presuppositions), it only makes understanding difficult, not impossible in principle. After learning, the would-be interpreter could become a bilingual, a person who can effectively understand both cultural languages in play. Obviously, such a language learning process is an extreme version of the adoptive approach to cross-cultural understanding within the model of propositional understanding. If so, does it mean that we have at least one case of propositional understanding which is more effective for cross cultural understanding than the hermeneutic model?

The language-learning approach is different from both the adoptive approach and the projective approach to understanding. While both the projective and the adoptive approaches are propositional in nature (both are based on propositional understanding), understanding through language learning is hermeneutic in character, which necessarily involves the hermeneutic circle between the interpreter's language and the alien language. For an interpreter to learn an alien cultural language, the interpreter cannot simply leave her/his own language behind. Our cultural language learner who tries to learn an alien cultural language is not a child with a mind of 'blank slate'. When the interpreter approaches the alien cultural language, she/he is already equipped with a set of cultural presuppositions brought with her/his own home cultural language. Experience and observations are theory-laden. It is impossible for our language learner with a prejudged mind to enter into the others' stream of experiences and truly 'go native'. Like Geertz's ethnographer, the language learner does not, and largely cannot, perceive what the native speaker of the cultural language perceives. Instead, the interpreter has to approach the language from the horizon of her/his own cultural language, or let the language speak to her/him who is already grounded within her/his own cultural tradition. Seeing from the perspective of Gadamer's hermeneutics, language learning in general, and the language acquisition of an alien cultural language in particular, is actually a process of hermeneutic interpretation. As Gadamer puts it:

It is impossible to understand what the work has to say if it does not speak into a familiar world that can be found a point of contact with what the text said. Thus to learn a language is to increase the extent of what one can learn. ... To have learned a foreign language and be able to understand it means nothing else than to be in a position to accept what is said in it as said to oneself. The exercise of this capacity for understanding always means that what is said has a claim over one, and this is impossible if one's own 'worldview and language-view' is not also involved (1989: 442).

\section{Conclusion}

It is time to summarize what we have learnt from our discussion of the hermeneutic experience of cross-cultural understanding between two distinct cultures. It is true that those who are brought up in a particular cultural tradition see the world in a different way from those who belong to other distinct cultural traditions. But in whatever cultural language we consider it, it is always a human language-world that presents itself to us. Every such cultural language is of itself always open to every possible insight, to 
every expansion of its own world picture, and accordingly open to being understood by others. This conclusion is the opposite of some forms of extreme relativism, including either the myth of the framework solipsism - what is incommensurable is enclosed within the walls of its own prison house built up by its unique tradition, language, and form of life - or the myth of unintelligibility - an alien conceptual scheme could be extremely remote from ours to the extent of being 'mutually unintelligible' or 'forever beyond our grasp'. On the contrary, if we follow Heidegger to give understanding an ontological orientation by interpreting it as an existential mode of existence of human existence, we start 'to recognize temporal distance as a positive and productive condition enabling understanding' (Gadamer 1989: 297). Similarly, although the conceptual distance between two distinct cultural languages does cause some difficulty in mutual understanding, it by no means sets insurmountable barriers between both sides. Instead, we should take this challenge as an invitation to genuine understanding, both understanding others and understanding ourselves. We can only truly understand ourselves by comparison with others and by testing our own prejudices during the process of understanding others. Therefore, cross-cultural understanding is always possible between any two distinct human cultures.

Be aware that what we have concluded is not that cross-cultural understanding is possible based on any model of understanding. It was found that the propositional model of understanding, no matter whether it is the projective approach or the adoptive approach, fails to achieve cross-cultural understanding, especially that between two distinct cultures. We have finally concluded that cross-cultural understanding is essentially hermeneutic - even in the case of cultural learning - not propositional, and cross-cultural understanding is hermeneutically possible. Gadamer's hermeneutic model of understanding provides us with a more effective approach of cross-cultural understanding.

\section{References}

Collingwood, R. G. 1940. An Essay on Metaphysics. Oxford: Clarendon Press.

Gadamer, H-G. 1970. 'Language and Understanding', Theory, Culture \& Society 23 (1), 13-27.

Gadamer, H-G. 1975. Truth and Method. trans. and eds. by G. Barden and J. Cumming, New York: Seabury Press.

Gadamer, H-G. 1979. 'The Problem of Historical Consciousness', in P. Rabinow and W. M. Sullivan (eds), Interpretive Social Science: A Reader. Berkeley: University of California Press.

Gadamer, H-G. 1985. 'Grenzen der Sprache', Evolution und Sprache: Uber Entstehung und Wesen der Sprache, Herrenalber Texte 66t, 89-99.

Gadamer, H-G. 1986, Gesammelte Werke, Vol. 2: Hermeneutik II: Wahrheit und Methode, Erganzungen, Registert.

Gadamer, H-G. 1989, Truth and Method, $2^{\text {nd }}$ edition. trans. by J. Weinsheimer and D. G. Marshall. New York: Continuum.

Geertz, C. 1973. The Interpretation of Cultures: selected essays. New York: Basic Books. 
Geertz, C. 1979. 'From the Native's Point of View: On the Nature of Anthropological Understanding', in P. Rabinow and W. M. Sullivan (eds), Interpretive Social Science: A Reader. Berkeley: University of California Press, 225-41.

Kroeber, A. and Kluckhohn, C. 1952. Culture: A Critical Review of Concepts and Definitions. Papers of the Peabody Museum of American Archaeology and Ethnology, Harvard University Volume XLVII, No. 1.

Taylor, C. 1982. 'Rationality,' in M. Hollis and S. Lukes (eds.), Rationality and Relativism. Cambridge: the MIT Press, 87-105.

Wang, X. 2002. 'Presuppositional Languages and the Failure of Cross-Language Understanding', Dialogue: Canadian Philosophical Review, 42 (1), 53-77.

Wang, X. 2003.'Conceptual Schemes and Presuppositional Languages', The Proceedings of the $21^{\text {st }}$ World Congress of Philosophy Volume 6 (Epistemology), editors, Stephen Voss and Dermot Moran, by Philosophy Society of Turkey, Ankara, 119-124.

Whorf, B. 1956. Language, Thought and Reality. Cambridge: The MIT Press.

Winch, P. 1958. The Idea of Social Science. New York: Humanities Press.

Wong, D. 1989. 'Three Kinds of Incommensurability', in Relativism, edited by M. Krausz. Notre Dame: University of Notre Dame Press, 140-58. 
Copyright of South African Journal of Philosophy is the property of Philosophical Society of Southern Africa (PSSA) and its content may not be copied or emailed to multiple sites or posted to a listserv without the copyright holder's express written permission. However, users may print, download, or email articles for individual use. 